\title{
El ecoturismo: ¿una nueva modalidad del turismo de masas?
}

\author{
Nora L. Bringas Rábago y \\ Lina Ojeda Revah ${ }^{1}$ \\ El Colegio de la Frontera Norte, \\ Tijuana
}

\section{Introducción}

A todo proceso de implantación de un modelo de desarrollo económico, lo acompañan cambios profundos en la esfera sociocultural, ambiental y territorial. Sobre todo, en el ámbito turístico, que se diferencia de otros en cuanto que, no son las mercancías sino los hombres quienes se desplazan para consumir in situ el producto.

Estos cambios están asociados con la introducción de un elemento ajeno a la cultura local, que es el turista, lo cual provoca modificaciones en la estructura económica, en las pautas de conducta de la población local y especialmente en la escala de valores. Como bien lo señala Marie-Françoise Lanfant, “con el turismo, lo que se importa a un país, no son sólo los turistas con sus maletas, sino un modelo de sociedad" (cit. en Cazes, 1992:98).

Este contacto, aparentemente banal, entre visitantes y visitados da origen a complejas relaciones que se cristalizan y adoptan formas diversas, dependiendo del grado de estas diferencias y de la intensidad de las relaciones. Evidentemente que mientras más grande sea el volumen de visitantes, más grandes serán tam-

${ }^{1}$ Las autoras agradecen el valioso apoyo y profesionalismo de Francisco Lares Serrano como asistente de investigación.

Economía, Sociedad y Territorio, vol. II, núm. 7, 2000, 373-403. 
bién los efectos que el turismo propicie en el ámbito social y cultural y en el ambiente.

Desde el periodo siguiente a la Segunda Guerra Mundial, el turismo de masas se ha perfilado como el tipo de turismo más importante en el ámbito mundial y todas las predicciones de la Organización Mundial del Turismo (ОМт) señalan que éste seguirá creciendo en importancia y número. Sin embargo, con el aumento de la conciencia ambiental, este tipo de turismo ha sido muy criticado y considerado como un depredador agresivo del ambiente. Por ello durante las últimas décadas ha crecido el interés por encontrar y desarrollar formas opcionales de turismo, casi todas realizadas en ambientes naturales. Un gran número de tipos de turismo alternativo ha aparecido en el mercado, creando confusión en su definición y sus efectos sobre el ambiente.

De entre ellos destacan por su importancia, el turismo basado en la naturaleza que en su modalidad de ecoturismo ha sido vislumbrado como una vía de generación de ingresos para el mantenimiento no sólo de áreas naturales protegidas, sino también de las comunidades en las que se lleva a cabo. Así mismo sobresale el turismo de aventura, que como su nombre lo indica, basa su éxito en la exploración de la naturaleza y, por ende, puede llegar a constituirse en un agente bastante nocivo para el ambiente, como es el caso de las carreras fuera de carretera llamadas Baja 1000 y Baja 500.

Es así que con el presente trabajo se pretende llamar la atención sobre el riesgo que pueden representar para el ambiente y para las comunidades donde se llevan a cabo, algunas formas de turismo alternativo, especialmente aquella variedad que justifica su existencia en los recursos naturales y que sin el menor recato produce efectos devastadores sobre el entorno natural. Para dar contenido a este argumento se parte del ejemplo de dos actividades turísticas que se realizan en la Península de Baja California: el uso de los vehículos recreativos de terracería en las carreras fuera de carretera, y la observación de la ballena gris en la reserva de la biosfera El Vizcaíno.

\section{Turismo: Contexto general}

En el periodo posterior a la Segunda Guerra Mundial, las mejores condiciones socioeconómicas de los trabajadores y la emergencia de las clases medias facilitaron el incremento de la deman- 
da de servicios turísticos, servicios que antes sólo estaban al alcance de un pequeño grupo privilegiado. La generación del baby boom fue la precursora de los viajes masivos en todo el mundo. Estos viajeros, la mayoría parejas jóvenes, buscaban un descanso contemplativo durante sus vacaciones disfrutando pasivamente del mar, el sol y la arena.

Durante este periodo, el modelo de desarrollo que se siguió fue la construcción de grandes hoteles verticales frente a las playas, los cuales contaban con todas las comodidades y los servicios dentro del mismo espacio. Lo anterior propició que cada hotel funcionara como un enclave, de tal manera que no se permitía el acercamiento entre los turistas y la comunidad receptora. Esta forma de organización del espacio costero orientado al turismo tradicional, propició un rápido crecimiento de estas zonas sin la adecuada planeación o medidas correctivas que mitigaran el impacto nocivo en el medio ambiente, provocado por la acelerada construcción y por el intenso uso a los que están expuestos estos ecosistemas por parte de los visitantes.

En la masificación del turismo ha jugado un papel fundamental el uso generalizado del transporte aéreo y la presión que han ejercido los tour operadores internacionales para rebajar las tarifas aéreas y hoteleras, obligando a salir del mercado a quienes no pueden enfrentar a la competencia. Esta horda de turistas que anda tras la "caza" de paquetes económicos y que organiza sus “viajes al instante” (Ungefug, 1992), se guía más por los precios bajos que por el destino a visitar, lo que ha propiciado un incremento de los flujos de visitantes hacia estos sitios, agudizando con ello los problemas de deterioro ambiental debido a la presión a que se ven sometidos estos frágiles ecosistemas.

Para ubicar en su justa dimensión el turismo de masas, baste señalar que en 1997 se movilizaron en el mundo 613 millones de turistas internacionales, mismos que generaron una derrama económica de casi 444 mil millones de dólares. Para el año 2000 se estima que habrá 692 millones de turistas viajando, quienes generarán divisas del orden de los 560 mil millones de dólares, cifra que irá en aumento en las décadas siguientes (OMT, 1998). Las proyecciones para el año 2020 indican que habrá 1600 millones de turistas internacionales viajando por el planeta. La tasa estimada de crecimiento anual sostenida será de 4.3\%. Así mismo se prevé que estos viajeros producirán una derrama económica de alrededor de 2 mil millones de dólares, considerando una tasa de crecimiento anual constante de $6.7 \%$. Se pronostica que 
ambos renglones crecerán a un ritmo mucho mayor que la expansión de la riqueza mundial proyectada en 3\% anual (OMT, 1998).

Dada la magnitud de los flujos turísticos y su creciente expansión, desde mediados de los años ochenta la preocupación por el medio ambiente comenzó a cobrar importancia. Para tratar de aminorar los efectos dañinos que el turismo de masas ha provocado, recientemente nació otra corriente que se ha denominado turismo alternativo, en la que los viajes a la naturaleza han ganado importancia.

\section{Los modelos vigentes: turismo tradicional y turismo alternativo}

A partir de lo expuesto arriba es posible distinguir dos tipos de turismo que prevalecerán en los próximos años: uno es el turismo de masas o tradicional y el otro es el turismo alternativo (véanse figura 1 y cuadro 1 ).

2.1. El turismo de masas o tradicional continúa siendo muy importante y tiende a incrementarse como consecuencia de la mayor disponibilidad de tiempo libre y por el aumento de vacaciones cortas. Este turismo en general compra paquetes baratos -que incluyen transportación aérea y hospedaje- y busca entretenimiento y diversión en las playas, sin que las características del destino cuenten tanto como el precio. Este turismo no tiene muchas expectativas acerca del viaje, y quienes lo practican normalmente son personas de ingresos medios y bajos. Este tipo de turismo generalmente corresponde al desarrollo tipo enclave, en el que el visitante interactúa poco con la comunidad receptora y su movilidad se reduce al avión-hotel-playa.

Lo anterior es importante para países como México, en los que generalmente el turismo se presenta como la punta de lanza para promover el desarrollo regional en zonas atrasadas económicamente y que cuentan con una gran diversidad de recursos naturales y culturales. No es fortuito el hecho de que durante el primer semestre de 1998, los ingresos por concepto de divisas turísticas (\$4 126 millones de dólares) superaron a las captadas por exportaciones petroleras (\$3874 millones de dólares), convirtiéndose el turismo en la segunda actividad generadora de divisas para el país (SECTUR, 1998b). 
La trascendencia del turismo para el desarrollo regional se deriva no sólo de los beneficios económicos que propicia en las comunidades locales, sino también de la generación de empleos y otros impactos favorables que produce en el plano social y cultural, y su cada vez mayor preocupación por la conservación de un medio ambiente sano, base de su éxito.

En 1997 llegaron a México poco más de 92.9 millones de visitantes. De este total, $73.5 \%$ correspondió a visitantes del día y sólo 19.4\% a turistas. En ese mismo año las divisas que entraron al país por concepto de visitantes internacionales fueron del orden de los 7593.7 millones de dólares, de los cuales $75.7 \%$ fue de turismo y el restante $24.3 \%$, de excursionistas. Lo anterior quiere decir que una quinta parte del turismo genera $75 \%$ de los ingresos. Por ello, a pesar de que México ocupa el octavo lugar como receptor de flujos turísticos, se encuentra en el peldaño 16 como destinatario de divisas (SECTUR, 1998a).

El gasto promedio del turismo mundial es de 730 dólares; en México es de menos de la mitad, 297 dólares, mientras que el de los excursionistas o visitantes del día es de 25 dólares. Estas cifras indican que en México no se está poniendo en valor la existencia de atractivos únicos, al parecer se está compitiendo por los precios bajos, lo cual es lamentable dada la gran ventaja comparativa que se tiene en recursos naturales y culturales.

2.2. El turismo alternativo es un segmento nuevo del turismo global que está cobrando cada vez mayor importancia. Este turismo trata de organizar su viaje hacia lugares desconocidos, conforme a sus necesidades y tiempos; busca "descubrir" sitios alejados del turismo de masas en ambientes naturales y que estimulen su desarrollo personal.

Este tipo de turismo, a diferencia del masivo, está dispuesto a pagar precios altos por la existencia de atractivos únicos, ya sean naturales o culturales. Este turismo ayuda a diversificar la oferta y orientarla hacia destinos diferentes a los de "playa", poniendo en valor el enorme abanico de atractivos naturales y culturales que existen en el mundo. Su importancia radica en que atrae el interés hacia zonas excepcionales, como las islas Galápagos en Ecuador o algunos sitios histórico-culturales; esta ventaja es la cualidad que los hace competir en el plano internacional.

Esta clase de turismo se divide entre quienes viajan atraídos por la existencia de recursos culturales y quienes basan su viaje en la naturaleza, aunque algunos combinan ambas modali- 
dades. El turismo basado en la naturaleza es todo tipo de turismo que se da en áreas naturales (Goodwin, 1996), y el cultural, en sitios históricos, desde museos hasta ruinas arqueológicas, así como la visita a comunidades locales. Ambos pueden ser clasificados a su vez como turismo rural o agroturismo, de aventura, ecoturismo y cinegético, aunque este último no es de corte cultural.

Cabe mencionar que las distinciones entre turismo rural, de aventura y ecoturismo, no siempre quedan claramente definidas y existen muchas áreas en las que se sobreponen (ver figura 1). El ecoturismo y el agroturismo generalmente contribuyen a mejorar el área como resultado de la actividad, con aportaciones monetarias y/o tiempo y trabajo. Por el contrario, en el turismo de aventura el ambiente natural contribuye al goce de la actividad realizada, pero ésta no necesariamente contribuye al mejoramiento general (idea adaptada de Orams, 1995, cit. en Burton, 1998). El turismo rural valoriza zonas rústicas, sus recursos naturales, patrimonio cultural, asentamientos rurales típicos, tradiciones locales y productos del campo, que de otra forma serían subaprovechados (Thibal, 1996).

Todos estos tipos de turismo alternativo y la vaga delimitación que existe entre ellos han creado no sólo confusión, sino que se ha utilizado el término "ecoturismo" de manera indiscriminada como producto comercial o "gancho" publicitario, suscitando una mayor confusión y haciendo creer que es una medida benéfica para el medio ambiente, lo que no necesariamente es cierto.

Pero, entonces, ¿qué es ecoturismo?, ¿cómo surge?, ¿qué busca el ecoturista?; ¿genera beneficios económicos? A lo largo de este documento se tratará de dar respuesta a estas preguntas. No sin antes mencionar que las fronteras conceptuales entre estos tipos de turismo no quedan claramente definidas. Esta yuxtaposición ha provocado que todas ellas se engloben bajo el término genérico de ecoturismo.

Entre los pioneros del ecoturismo en México destaca Ceballos Lascurain (1988:13-14), quien lo ha definido como

[...] el viajar a áreas naturales relativamente poco perturbadas o contaminadas, con el objetivo específico de estudiar, admirar, gozar los paisajes, su flora y fauna silvestres, así como cualquier manifestación cultural (tanto pasada como presente) encontrada en estas áreas. El turismo ecológico implica una apreciación científica, estética o filosófica, sin que el turista sea necesariamente un científico, artista o filósofo profesional. 
Por su parte, Támara Budowski (1989:75) señala que

[...] la búsqueda de experiencias profundas, enriquecedoras características de los años 60, sumada a la popularidad de las actividades al aire libre de la década de los 70 y la preocupación despertada en los 80 por la salud, la alimentación natural y una buena condición física, terminaron de sentar las bases para el desarrollo del ecoturismo.

Al cobrar mayor fuerza la conciencia ambiental y dado que en los últimos años el turismo había sido duramente criticado por ser una de las actividades más depredadoras de la naturaleza, el medio ambiente se convirtió en motivo de pesimismo y entusiasmo. Pesimismo por la preocupación del deterioro ambiental, y optimismo porque deja abierta una ventana para conservar los recursos naturales, base de su éxito. En este contexto, el ecoturismo emerge como una posibilidad en la que se podría conciliar la ecología con la economía, empezando así a difuminarse el halo peyorativo que rodeaba al turismo.

$\mathrm{Al}$ mismo tiempo, existen quienes consideran al ecoturismo como el ejemplo más cercano de lo que puede ser un "desarrollo sustentable" (Marajh, 1992), que implica respetar y cuidar los recursos naturales de hoy, sin comprometerlos para las generaciones futuras, pero que permita a las comunidades locales vivir de esos recursos, no por su explotación indiscriminada sino mediante su uso racional, al obtener ingresos económicos por su conservación. La idea es que si se respetan los rangos de funcionamiento de los ecosistemas, junto con otras medidas protectoras, se puede coadyuvar a generar un uso sustentable y económico de las áreas naturales. El ecoturismo promete ser una parte importante de los programas de desarrollo sustentable debido a su decidida motivación para conservar sitios naturales (Mendelsohn, 1994).

Bajo esta perspectiva, el ecoturismo es concebido también como un elemento catalizador para que las áreas rurales obtengan fuentes opcionales de ingresos y no tengan que destruir los recursos para poder subsistir.

Más tarde el ecoturismo cobró fuerza como una nueva corriente que ayuda a proteger áreas naturales. Según Karen Ziffer (1989:1) el ecoturismo busca atraer a una parte del mercado global de turismo hacia las áreas naturales y destinar ingresos a fundaciones locales de conservación y así propiciar el desarrollo económico. Elizabeth Boo (1990:xIV) coincide con Ziffer al señalar que desde el punto de vista de la conservación, el ecoturismo 
"puede proveer una justificación económica para la conservación de áreas que de otra manera no recibirían ninguna protección”. Por el contrario, algunos críticos creen que "los conservacionistas intoxicados por las promesas del ecoturismo abren las puertas a la destrucción de muchas zonas que están tratando de proteger” (Ziffer, 1989).

En suma, todos estos enfoques tratan de llamar la atención sobre la trascendencia que tienen los viajes a la naturaleza y su creciente importancia como parte del mercado global del turismo. Se trata de acentuar el enorme potencial económico que pueden tener algunos recursos naturales, si en lugar de destruirlos se protegen, o el caso de algunas especies de animales carismáticos que representan más valor económico si se dejan vivos para el regocijo de visitantes, que si los matan cazadores furtivos.

Elizabeth Boo señala que la industria turística está viviendo un auge como consecuencia del incremento de los viajes a la naturaleza, gracias al ecoturismo. Los turistas están visitando, como nunca antes, parques y reservas; con esta experiencia tratan de comprender y apreciar mejor la naturaleza (Boo, 1992). Si bien es cierto que no existen estadísticas específicas para medir el flujo de ecoturistas que visitan las diferentes zonas del mundo, ni la derrama generada en las comunidades receptoras, por lo menos existen algunas evidencias que permiten vislumbrar la importancia que ha cobrado este fenómeno. Entrevistas realizadas por Karen Ziffer a los tour operadores sugieren que el ecoturismo es un segmento del mercado en constante expansión, dado que registra un crecimiento cercano a 20\% anual (Ziffer, 1989:1).

El sistema de Parques Nacionales de los Estados Unidos, primero en su estilo en el ámbito mundial, recibió 270 millones de visitantes en 1989. Los parques estatales captaron poco más de 500 millones. En Canadá la afluencia a los parques nacionales y estatales fue de 20 y 47 millones, repectivamente (Baker, 1990 y Prescott-Allen, 1986, cit. en OMT y PNUMA, 1992). Los observadores de pájaros en Point Pelee National Park de Ontario, Canadá, gastaron 3.8 millones de dólares durante 24 días, de los cuales 2.1 fueron invertidos localmente (Mendelsohn, 1994). De lo anterior se deriva el gran potencial económico que representa el ecoturismo.

La importancia que empezó a cobrar el turismo de aventura o ecoturismo propició que tan sólo en 1986 existieran en los Estados Unidos aproximadamente 5000 tour operadores que ofrecían guías y agentes de viajes especializados en viajes a la natura- 
leza (Wall Street Journal, cit. en Budowski, 1989). El turismo de aventura o ecológico es el segmento de mayor crecimiento en los Estados Unidos; los tour operadores estiman que de 4 a 6 millones de estadounidenses cada año realizan viajes al extranjero en busca de áreas naturales; el costo promedio del viaje a la naturaleza, sin incluir la tarifa aérea, fue de 3000 dólares, de lo que se deduce que los ingresos que quedan en los países receptores por este concepto es de casi 12 mil millones de dólares (Wall Street Journal, cit. en Budowski, 1989).

Algunas estimaciones señalan que el gasto total de los visitantes de Europa y los Estados Unidos hacia las áreas naturales de los países menos desarrollados, es de casi 1.7 mil millones de dólares (Ziffer, 1989). Para países como Costa Rica, Ecuador, Belice, Ruanda, Kenia y otros, los viajes a la naturaleza tienen una gran importancia económica (Boo, 1990; Ziffer, 1989; Budowski, 1989; OMT, 1992; Marajh y Meadows, 1992; entre otros).

En 1988 casi 15 millones de turistas visitaron América Latina, muchos de ellos llegaron atraídos por la flora y fauna de las áreas naturales protegidas; tan sólo en Belice los visitantes pasaron de 99000 en 1987 a 215442 en 1991; incrementos similares se han registrado en Costa Rica (Mendelsohn, 1994). En el Parc National des Volcans de Ruanda los turistas que van a ver los gorilas generan un millón de dólares sólo por cuotas de entrada al parque (OMT y PNUMA, 1992). El ecoturismo genera 500 millones de dólares para Costa Rica (Padget y Begley, 1996).

Se ha hablado mucho de que la mejor forma de proteger ciertas especies de animales es precisamente gracias a su rentabilidad económica. Modelos económicos aplicados en el Parque Nacional Amboseli de Kenia indicaron que por sólo observar un león se obtuvieron ingresos anuales cercanos a 27 mil dólares. El valor de una manada de elefantes fue estimado en 610 mil dólares al año también por concepto de turismo ecológico (OMT y PNUMA, 1992). Lo anterior muestra la importancia que tiene el turismo de tipo ecológico para la conservación de la vida silvestre y sobre todo por los ingresos económicos que genera en la comunidad receptora.

Pero para que el ecoturismo sea una efectiva estrategia de conservación, quienes planean el uso del suelo deben encontrar en él su rentabilidad económica por encima de otros usos del suelo. Por ejemplo: el Parque Nacional Amboseli en Kenia obtiene por turismo ecológico 40 dólares por hectárea al año; si estos 
mismos terrenos se destinaran a la agricultura se obtendrían 80 centavos por hectárea (OMT y PNUMA, 1992).

\section{¿Son excluyentes estos modelos?}

El ecoturismo, a diferencia del turismo tradicional, requiere poca inversión en infraestructura y una alta inversión en capacitación, conocimiento, organización e información, es decir, el ecoturismo demanda una mayor preparación y capacidad para enfrentar la competencia, que está basada en la existencia de recursos excepcionales, de ahí el alto costo que pagan los ecoturistas por disfrutar estos recursos, pues a diferencia de los centros tradicionales de playa que ofrecen una oferta estandarizada, la posibilidad de sustituir un recurso natural único es casi imposible.

Hoy día el turista busca obtener nuevas vivencias y experiencias en el plano personal mediante la visita a sitios desconocidos, a zonas rurales y practicando actividades diferentes al aire libre y en un entorno natural; por ello el modelo alternativo busca la diferenciación del producto con respecto a otros lugares (Pearce, 1988), o la complementación con formas convencionales del quehacer turístico, demandando prácticas nuevas que lo retroalimenten y permitan su superación como individuo al interactuar y experimentar en la comunidad, por eso organizan ellos mismos su programa de viaje, a diferencia del turismo tradicional en el que el viaje es preestablecido y no se interactúa con la población local.

El modelo convencional centra su promoción en los medios de comunicación y su criterio de selección son los niveles de ingreso, en cambio el turismo alternativo busca segmentos o nichos especializados del mercado. Por eso en el primero se acentúa el crecimiento, lo que deviene en una pérdida de control, mientras que en el segundo se privilegia la capacidad de la organización, lo cual le otorga un mayor grado de complejidad.

Si bien en la práctica el ecoturismo está cobrando cada vez más fuerza, no se puede decir que esta nueva forma de hacer turismo vaya a desplazar al turismo de masas; por el contrario, este último crece a pasos agigantados y todas las estimaciones realizadas le auguran un futuro boyante. En este contexto, dada la fragilidad de los ecosistemas y la exposición a la que estarán sujetos por esta masa de visitantes, el reto ambiental más importante que deberán enfrentar los responsables de la planificación 
turística, será encontrar formas novedosas para lograr que los grandes consorcios hoteleros participen activamente en un uso más racional y sustentable de los recursos que promueven. Sólo así los efectos desfavorables sobre el entorno podrán ser menores y menos dañinos, pues cabe recordar que por mínimos que sean los flujos hacia las áreas naturales, siempre provocan un cambio (Wall, 1997).

Para que el turismo sea sustentable se tiene que

[...] desarrollar y mantener una comunidad o ambiente, de tal forma y a tal escala que permanezca viable en un periodo de tiempo indefinido y que no degrade o altere el ambiente (humano y físico) circundante, a tal grado que impida el éxito y desarrollo del bienestar (sic) de otras actividades en el proceso (Butler, 1993:29).

Si bien es cierto que esta actividad ha contribuido a generar divisas, también lo es que éstas generalmente se regresan a los países de origen de los tour operadores. Como ya es conocido, la mayor parte de los países emisores de flujos turísticos provienen de los países desarrollados del hemisferio norte, que es donde se concentran los grandes tour operadores que controlan el mercado. La mayoría de los gastos que estos viajeros realizan van a transportación, hoteles, comida y bebida, mismos que casi siempre son cubiertos en su propio país de origen. En su destino, casi siempre áreas silvestres, el viajero encuentra pocas opciones para comprar, pues parafraseando a Wall (1997), "por definición, es difícil gastar dinero en la naturaleza".

En consecuencia, tanto para los tour operadores como para las áreas receptoras, siempre estará latente la posibilidad de incrementar sus ganancias mediante el aumento del número de visitantes hacia estas zonas, con el argumento de que "donde comen dos comen tres”. Así mismo, la llegada de visitantes a zonas silvestres inevitablemente creará nuevas demandas de infraestructura y servicios, con lo cual la espiral de oferta y demanda empieza a ir en aumento. Por lo que siempre existirá el peligro de que el ecoturismo se deje seducir por los encantos (\$) del turismo de masas. ¿Será que el ecoturismo no es más que un estado precursor del desarrollo turístico? (Wall, 1997).

Es así que el ecoturismo ha sido visto como una alternativa económica que contribuye a la conservación de la biodiversidad, especialmente como fuente de ingresos para el mantenimiento de áreas naturales protegidas. Sin embargo, la conservación en sí misma se enfrenta a varios problemas, que valdría la pena consi- 
derar si se pretende lograr que el binomio ecoturismo-conservación sea viable.

\section{III. ¿Por qué limitar la conservación a las áreas naturales protegidas?}

A la fecha, la visión más generalizada de la conservación de la biodiversidad y de los ecosistemas naturales, ha estado restringida sobre todo a la creación de áreas naturales protegidas. Con ello normalmente se apartan algunas extensiones del territorio y se ponen fuera del alcance del desarrollo humano. Aunque resulta necesario mantener esta estrategia, dada la velocidad a la que en la actualidad se pierden los ecosistemas naturales y se extinguen especies, a mediano y largo plazos no será suficiente. Esto se debe a diversos problemas ecológicos, sociales y económicos que se generan dentro y fuera de dichas áreas y que se encuentran íntimamente entrelazados, pero que normalmente son tratados de forma independiente. Por ello, la solución de los problemas de conservación "no puede ser puntual, no radica en el establecimiento aislado de un área protegida o en la protección compulsiva de una especie animal o vegetal, sino en la planificación integral de la conservación y el desarrollo al nivel regional y local” (Mann, s/f:27).

\subsection{Problema ecológico}

Uno de los principales conflictos ecológicos a los que se enfrentan muchas de las áreas naturales protegidas, es el hecho de que sus dimensiones son pequeñas y aisladas. En lo que concierne a su tamaño, hoy día se reconoce que la mayoría de ellas no son lo bastante grandes como para preservar la diversidad existente, ni los factores que la determinan. Este problema se presenta no sólo en cuanto a las especies, sino a los hábitats diferentes que permitan a las propias especies ampliar su rango de adaptación para enfrentarse a posibles perturbaciones, tanto naturales como provocadas por el hombre.

La premisa anterior se basa en la modificación de la teoría ecológica desde una visión de equilibrio, al reconocimiento de la existencia de procesos de disturbios naturales, incertidumbre y riesgo que provocan que los ecosistemas cambien continuamente 
sobre ciertos rangos que varían en tiempo y tamaño. Se considera disturbio a las "fluctuaciones ambientales o eventos destructivos, sean o no percibidas como 'normales' en un sistema" (Pickett y White, 1981:6); esto es, al evento que altera de manera significativa el patrón de variación de la estructura y función de un sistema.

Los regímenes de incendios naturales, las inundaciones, los huracanes, las sequías, la depredación, las enfermedades, las plagas y la intervención humana, son algunos ejemplos que pueden ser considerados como disturbios. Su periodicidad, magnitud y distribución espacial varían en el tiempo y no son fáciles de predecir. Los disturbios producen áreas con características diferentes a su entorno, en cuanto a su disponibilidad de recursos y estructura, desviando a las comunidades de su camino sucesional original y produciendo heterogeneidad. Las fluctuaciones de estos eventos en el tiempo contribuyen además a aumentar la heterogeneidad, es decir que son necesarios para mantener la diversidad.

En lo que atañe a su aislamiento, la mayoría de las áreas protegidas están cada vez más alejadas unas de otras, con lo cual la probabilidad de que protejan especies de amplia distribución a largo plazo es muy baja. La condición aislada de las áreas protegidas también disminuye la probabilidad de intercruzamiento de las diferentes poblaciones de una misma especie, reduciendo así su grado de adaptabilidad a los disturbios y por lo tanto limitando su supervivencia (Peck, 1998).

Diversos estudios han demostrado que los principales problemas existentes dentro de las áreas protegidas se originan en actividades realizadas fuera de sus límites. Esto conduce a tratar de analizar lo que sucede fuera de las áreas protegidas.

La fragmentación de hábitats es el proceso de subdivisión de un hábitat continuo en piezas más pequeñas, y sucede en sistemas naturales provocado principalmente por los disturbios tanto naturales como artificiales. No obstante, alrededor del mundo los ecosistemas terrestres han sufrido diversos grados de desintegración como resultado de la conversión del uso del suelo realizada por el hombre, que rompió la continuidad de los hábitats naturales (Noss, 1996). Actualmente se reconoce que la fragmentación antrópica ha tenido efectos de deterioro en algunos componentes de la biota (como el declive de la diversidad biológica) debido a la pérdida de hábitat original, reducción del área del mismo, su aislamiento, el aumento proporcional de fronteras con 
relación a las condiciones del interior, y un incremento de ambientes no adecuados dentro del paisaje (Andren, 1994).

Empero, se podría decir entonces que la fragmentación de hábitats naturales es un mal necesario para el desarrollo del ser humano, y por lo tanto debe considerarse como un proceso que seguirá en aumento y cuya influencia alcanzará cada vez más a las áreas protegidas. Llegará un momento en el que éstas serán pequeñas islas, inmersas en un medio hostil que acabará por destruirlas a mediano plazo.

Ahora bien, cuando se propone al ecoturismo como alternativa viable de financiamiento en áreas protegidas, en general se da por hecho que es una actividad ambientalmente benigna. Sin embargo, esta actividad, al igual que cualesquier tipos de turismo trae consecuencias. De hecho, autores como Wall (1997) mencionan algunos de los efectos destructivos que esta actividad puede tener en el ambiente:

1. El ecoturismo regularmente se dirige sobre todo a lugares muy especiales como las áreas protegidas, las cuales si fueron elegidas para su conservación, en parte se debe a la fragilidad que presentan frente a la intervención.

2. El ecoturismo no considera en sus itinerarios el evitar momentos críticos en la naturaleza, sino que en ocasiones es lo que busca. Ejemplos de ello son las épocas de apareo o cuando los predadores persiguen a sus presas.

3. El ecoturismo da por hecho que la relación entre el volumen de uso y los impactos asociados es lineal. No obstante, es mucho más probable que esta relación sea curvilínea o escalonada, y que inclusive pocos visitantes puedan generar impactos.

\subsection{Problema socioeconómico}

Desde un punto de vista socioeconómico, en países como los Estados Unidos es posible intentar preservar áreas totalmente ajenas a la intervención humana, bajo leyes como el Wilderness Act decretado en 1964. Pero en México la población es parte de la naturaleza y requiere de ella para su subsistencia, como lo demuestra la histórica inclusión de terrenos ejidales dentro de los parques nacionales. Es por ello que en México cobró importancia la modalidad de área protegida de reserva de la Biosfera, diseñada como un área núcleo sin perturbación humana y un área de 
amortiguamiento que permite actividades basadas en el manejo adecuado de los recursos.

No obstante, las reservas de la biosfera tampoco han quedado exentas de conflictos. Parte se debe a la falta de aplicación y diseño de planes de manejo adecuados, pero el principal problema radica en que el área, con todo y su población, es extraída parcialmente de los parámetros del medio económico que le rodea, al serle impuestas otras condiciones de sustentabilidad ecológica. Reglas que se encuentran en contraposición con las fuerzas económicas que presionan en el sentido de siempre obtener un mayor rendimiento y ganancias en el menor tiempo posible, cuando la naturaleza requiere de tiempos y espacios conservados para poder recuperarse.

En este sentido, se puede equiparar la protección aislada de un elemento biológico con el desarrollo sectorial tradicional: ambas presentan simplificaciones tendenciosas a favor de un desarrollo parcial que en la práctica se ha demostrado ineficaz (Mann, s/f:27).

Otro problema tiene que ver con la insistencia de valorar económicamente a la naturaleza. Aunque muchos países, incluido México, comienzan a considerar la incorporación de cuentas ambientales dentro de su economía, la naturaleza compleja del ambiente con un sinnúmero de interacciones siempre será subvalorada. Se debe evitar caer en la idea de que el ambiente es divisible en recursos discretos y propiedades cuyos valores son estrictamente humanos, y por lo tanto están valorados fuera del contexto de su sistema original.

El que, la naturaleza tiene un valor intrínseco y éste descansa en la integridad del todo y no en el uso económico de sus partes, y que valorar sólo las partes que tienen utilidad para el hombre automáticamente subestima los efectos de la explotación de los recursos naturales (Lineham y Gross, 1998:213).

Si las áreas naturales protegidas no son suficientes para mantener la diversidad, y si de veras el ecoturismo fuese una forma inicial del turismo de masas, entonces habría que visualizar el turismo alternativo en general dentro y fuera de las áreas protegidas. Para ello se utilizarán como ejemplos el caso de las carreras fuera de carretera y los efectos nocivos que puede tener sobre el ambiente la observación de la ballena gris en la reserva de la biosfera El Vizcaíno. 


\section{Dos ejemplos de turismo basado en la naturaleza en la península de Baja California}

Con el surgimiento del modelo de turismo especializado o alternativo se ha extendido la idea de que el turismo basado en la naturaleza no tiene efectos dañinos para el ambiente, que puede ser mantenido como de bajo impacto indefinidamente y que contribuye al desarrollo de comunidades locales. Sin embargo, en el caso de la península de Baja California los ejemplos que se presentan a continuación indican que el turismo basado en la naturaleza no siempre se acompaña de un aura benéfica con la que se le quiere santificar.

\subsection{Carreras fuera de carretera en Baja California: Baja 500}

En el estado de Baja California se realizan anualmente dos de las carreras fuera de carretera más conocidas no sólo en el norte del país, sino en el sur de los Estados Unidos. Éstas adquirieron relevancia a partir de las restricciones impuestas por el gobierno estadounidense al uso de los vehículos recreativos de terracería (Off road o VRT), y las presiones generadas por los grupos ecologistas por los daños ambientales que estos vehículos provocan; fue así que los organizadores de este tipo de actividades voltearon sus ojos hacia tierras mexicanas; en especial las del estado de Baja California se convirtieron en un paraíso para los conductores de los VRT y los promotores de carreras. ${ }^{2}$ En este sentido, la Península ofrece más oportunidades de aventura debido a lo accidentado de su topografía, la diversidad de sus paisajes, lo prístino de sus tierras y la cercanía geográfica con los Estados Unidos.

Las carreras Baja 1000 y Baja 500 son consideradas como encuentros deportivos y recreativos que se adscriben dentro del turismo alternativo basado en la naturaleza, como lo es el turismo de aventura. La carrera se realiza a campo traviesa y el atrac-

${ }^{2}$ Durante la década de los sesenta el uso de los VRT se convirtió en una moda a seguir, particularmente en los desiertos del estado de California en los Estados Unidos. Sin embargo, su popularidad comenzó a decrecer al difundirse las perturbaciones que tales vehículos ejercían principalmente sobre los desiertos. Las presiones de los grupos ecologistas estadounidenses se dejaron sentir muy pronto. Con ello, para 1972, por medio del Executive Order 11644 promovido por el presidente de los Estados Unidos, se restringió el uso de estos vehículos en tierras de propiedad federal, y más tarde con el Executive Order 11989 decretado en 1977, se cerró en definitiva el paso de los VRT a ciertas áreas (Kockelman, 1983a). 
tivo principal consiste en buscar caminos o brechas muy poco transitados, de ahí que gran parte de la ruta sea sobre zonas ejidales que aseguren caminos difíciles y, en general, condiciones inhóspitas. Entre más accidentado sea el terreno mayor es el reto y la aventura. La ruta varía año tras año y ello se debe, por una parte, a que los organizadores quieren asegurar un grado de dificultad para los participantes, y por otra, a que varios de los ejidatarios de la región quieren que la carrera atraviese sus tierras para cobrar por ello una pequeña cantidad en dólares.

La Baja 1000 y la Baja 500 atraen a una gran cantidad de participantes y espectadores, en su mayoría extranjeros. Este flujo de visitantes, que si bien no ha sido medido en su cabal magnitud, tiene efectos directos sobre el medio ambiente y la actividad turística, comercial y de servicios de las localidades por donde pasa la carrera. ${ }^{3}$ Tan sólo en 1989 la Secretaría de Turismo del Estado de Baja California (SECTURE) reportó que la Presidente Score Baja 500 Internacional tuvo una participación de 230 competidores y una afluencia de casi 4000 visitantes. El gasto per cápita fue de 148 dólares, y se destinó principalmente a restaurantes, gasolina, licorerías, bares y hoteles, entre otros; generando una derrama económica de 590360 dólares, durante una estancia promedio de poco más de dos días (55 horas). Datos de 1997 señalan que dicha carrera atrajo a 197 corredores, además de cuatro personas en promedio como parte del grupo de apoyo, por lo que se calcula una participación de 985 visitantes asociados directamente a la carrera y una afluencia diaria de 2903 visitantes. La estancia promedio del torneo deportivo es de tres días, lo que se traduce en una afluencia estimada de 8709 visitantes, en su mayoría extranjeros (SECTURE, 1997).

En lo referente a la derrama económica que genera este tipo de actividades, se sabe que en el caso de Ensenada en 1997, en 53\% de los establecimientos turísticos entrevistados se señaló que las carreras fuera de carretera no representaron un incremento significativo en sus ingresos. Así mismo, otro $16.3 \%$ de los entrevistados manifestó que sus ingresos permanecen similares tanto durante el transcurso del certamen deportivo como a lo largo del año. La derrama económica generada por esta carrera en 1997 fue de casi 4693347.10 pesos, ingresos menores a los

${ }^{3}$ Las localidades que se ven beneficiadas económicamente por la realización de dichas carreras son, en orden de importancia, Ensenada y San Felipe, pues ambas ciudades son las que cuentan con la mayor infraestructura de servicios turísticos y comerciales. 
propiciados por la Carrera Ciclista Rosarito-Ensenada, con duración de solamente un día (SECTURE, 1997).

Si bien es cierto que este tipo de carreras generan derrama económica, también lo es que gran parte de las divisas se regresan al país de origen de los organizadores: los Estados Unidos. La Score International se encarga de cobrar por cada participante y paga una cantidad mínima a los ejidatarios por cada milla de su terreno por el que atraviesa la carrera; en 1989 les pagó 32 dólares por milla y en 1999 sólo 25. En la realización de cualquier torneo, ya sea deportivo o no, siempre hay ganadores y perdedores. Generalmente quienes ganan son los organizadores y promotores, cuyas ganancias no son por la cuota de inscripción en sí, sino por la venta promocional de las marcas de autos participantes. Para algunas marcas de autos y accesorios utilizados como Toyota, Nissan, Good Year, Firestone, entre otros, el hecho de competir y ganar en una de las principales carreras fuera de carretera les asegura un incremento en sus ventas; así se establece la competencia entre marcas, que en términos de mercadotecnia obtienen buenos resultados.

Además de los pocos beneficios económicos que dejan en las localidades y ejidos por donde pasa la carrera, los efectos del turismo en el ámbito ecológico casi siempre resultan desfavorables, situación que se agrava por la falta de una adecuada legislación que reglamente y controle la cuestión ambiental conjuntamente con el turismo. Sobre los efectos que provoca el uso de los VRT sobre los ecosistemas, se sabe que su constante paso destruye la vegetación y aumenta la susceptibilidad del suelo a la erosión (Wilshire, 1983; Lathrop y Rowlands, 1983). Como resultado se inhibe el crecimiento de la vegetación y el ambiente en general se torna más hostil para la flora y fauna (Dregne, 1983). El suelo erosionado puede ser transportado a cuerpos de agua superficiales, en los que contribuye a la carga de sedimentación y a obstruir el cauce de arroyos (Kockelman, 1983b).

Otro efecto nocivo de los VRT es el ruido que generan, no solamente por las molestias que pueden causar a la población que vive en los alrededores, sino porque alteran en gran medida los ciclos de vida naturales de muchas especies animales (Brattstrom y Bondello, 1983; Escofet y Carvacho, 1988).

En la actualidad, el área más usada por estos vehículos se extiende al Oeste, desde la frontera hasta unos 100 kilómetros al sur de Ensenada, por el lado del Golfo hasta San Felipe y por la sierra hasta San Pedro Mártir (Pakhurst, 1988), abarcando casi 
todos los tipos de vegetación presentes en el estado y afectando por ende un área muy extensa. Además, las rutas de las carreras fuera de carretera Baja 1000 y Baja 500 atraviesan por el área de distribución marginal ${ }^{4}$ del borrego cimarrón, que hoy día es una especie muy apreciada por estar en peligro de extinción y se encuentra bajo protección especial (Martínez y Eaton González, s/ f) (véase mapa 1).

Lo paradójico de lo anterior es que en 1997 se dio a conocer el Programa de Ecoturismo en Áreas Naturales Protegidas (ANP) de México, elaborado por la SEMARNAP y la SECTUR, con lo cual parece inapropiado que al mismo tiempo se permita el uso de VRT en forma indiscriminada. Acaso por no encontrarse el borrego cimarrón dentro de una ANP ¿no tiene derecho a continuar su especie? Resulta a todas luces contradictorio que por una parte se trate de proteger al borrego cimarrón, limitando el número de permisos para su caza, y por la otra, se permita la realización de eventos como las carreras fuera de carretera, que bajo el argumento de una gran derrama económica generada, transgrede el hábitat natural de una especie en peligro de extinción. Es importante llamar la atención sobre este fenómeno, dado que su realización se encubre bajo la capa del turismo ecológico o basado en la naturaleza, lo cual puede ser engañoso.

Para el estado de Baja California, el sistema de áreas protegidas establecido es bastante extenso. Constituye 27\% de su territorio. ${ }^{5}$ Pero, a pesar de su gran extensión, desde el punto de vista de tipos de ecosistemas tiene poca representatividad. Por ejemplo, la protección de zonas costeras del Pacífico se restringe a las áreas que cubren las islas del Pacífico y del Golfo de California y la de la reserva de la biosfera del Alto Golfo. En ellas faltaría por conservar tipos de vegetación como el matorral esclerófilo costero, el cual se localiza exclusivamente en el noroeste del estado (Flores y Gerez, 1988), y aquellos ecosistemas riparios ${ }^{6}$ que logran salir hasta el mar (véase mapa 1). Además, las áreas protegidas del estado están aisladas unas de otras y no se vislumbra la intención de establecer un sistema que las conecte.

Por desgracia, los problemas a los que se enfrentan las áreas protegidas en México no sólo se limitan a la mala representativi-

\footnotetext{
${ }^{4}$ El área de distribución marginal es aquella que se establece uniendo los puntos en los que se han realizado observaciones de la especie en cuestión, por lo que no necesariamente la especie se encuentra dentro de esos límites.

${ }^{5}$ Sin considerar las áreas que comparte con otros estados.

${ }^{6}$ Ecosistemas riparios son aquellos que se desarrollan en las riberas de los ríos.
} 
dad biogeográfica y a su aislamiento, sino también a la falta de respaldo económico, reflejado en una carencia casi total de vigilancia, entre otros factores. Con ello, es muy probable que la mayoría de los vehículos recreativos de terracería penetren en estas áreas y susciten daños a la naturaleza sin ningún control.

\subsection{Observación de ballena gris en la reserva de la biosfera $\mathrm{El}$ Vizcaíno}

En las cálidas bahías de las costas de la península de Baja California, localizadas en el Pacífico Norte, año con año llegan las ballenas grises a procrear a sus ballenatos. Las lagunas de Guerrero Negro, Ojo de Liebre, San Ignacio, y la Bahía Magdalena son las más importantes. Aunque Bahía Magdalena alberga menos número de ballenas, en ella se congregan más densamente, en especial en el área de Boca de Soledad (Fleischer et al., 1984, cit. en Dedina y Young, 1995).

En 1972 México sentó un precedente al establecer para su protección, por decreto presidencial, el Santuario de la Ballena Gris en laguna Ojo de Liebre en Baja California (Diario Oficial, 1972, cit. en Dedina y Young, 1995). Con decretos subsecuentes se crearon otras áreas protegidas o incrementaron las ya existentes, siendo el último en 1988 cuando se estableció la reserva de la biosfera El Vizcaíno, que incluye a la laguna Ojo de Liebre y a la de San Ignacio (Diario Oficial, 1988, cit. en Dedina y Young, 1995).

La observación de ballenas era una actividad incipiente a mediados de los años ochenta y generaba sólo 5 millones de dólares a 10 países. Hoy día esta actividad atrae a más de 5 millones de turistas y genera más de 500 millones de dólares. Para Baja California la oficina de planeación del municipio de Comondu estima que el turismo alrededor de la ballena gris creció 300\% entre 1993 y 1994 (Municipio de Comondu, 1994, cit. en Dedina y Young, 1995). Tan sólo en Bahía Magdalena confluyeron en 1994 más de 10000 turistas (Dedina y Young, 1995) y para 1996 ya se esperaban 20 000, esto es, casi el doble (Padget y Begley, 1996), lo cual resulta alarmante, dadas las características tan pequeñas de la laguna.

Según investigadores de la Universidad de Arizona (Padget y Begley, 1996), en 1994 el ecoturismo generó 4.7 millones de dólares en Bahía Magdalena, de los cuales se quedaron solamen- 
te 33000 a empresas y asalariados mexicanos. Esto se traduce en que menos de $1 \%(0.7 \%)$ de los ingresos generados por este concepto se quedan en las comunidades receptoras y el restante $99.3 \%$ se regresa a los tour operadores, la mayoría localizados en el vecino estado de California, Estados Unidos. Cabe resaltar además que de los permisos emitidos por el Instituto Nacional de Ecología (INE) para un total de 13 botes, 6 fueron para residentes locales y 7 para extranjeros, y que los 44 mexicanos empleados obtuvieron alrededor de 1400 dólares durante la temporada, constituyendo casi la mitad de sus ingresos anuales (Dedina y Young, 1995).

En el caso de la laguna de San Ignacio, las cifras calculadas por Dedina y Young (1995) para el mismo año indican que los paquetes turísticos para observar ballenas generaron 3.3 millones de dólares, de los cuales sólo 26000 dólares, es decir $0.78 \%$ llegó a las comunidades locales. Estos mismos autores reportan que en 1994 el INE permitió operar en la laguna de San Ignacio a 16 botes, 12 extranjeros y 4 residentes locales; los 22 mexicanos empleados recibieron entre 2000 y 6000 dólares equivalentes a entre 25\% y 50\% de sus ingresos anuales (Dedina y Young, 1995).

Desafortunadamente, hasta la fecha no se conocen los efectos que este creciente turismo puede llegar a tener sobre la ballena gris y su descendencia. Sin embargo, si la tendencia de crecimiento de este tipo de turismo continúa en ascenso y si no se toman las medidas necesarias para evitar la afluencia masiva hacia este santuario, es posible prever los efectos nocivos sobre este ecosistema y la especie que se trata de proteger.

\section{Comentarios finales}

El turismo en las sociedades modernas ha actuado como reforzador de la interacción cultural de los pueblos, en muchos de los casos este es el factor que motiva a la gente a viajar; el hecho de estar en contacto con una cultura distinta es una experiencia que resulta alentadora, que estimula la capacidad creativa del individuo y por consiguiente se constituye en condición esencial para la realización de las más grandes potencialidades humanas.

Como se señaló en párrafos anteriores, la importancia económica que el turismo tiene se reconoció en la década de los sesenta y desde entonces ha sido el propio gobierno el que ha tomado bajo su responsabilidad la planeación y el financiamiento 
de los destinos turísticos. Si bien es cierto que el turismo ha significado un factor de desarrollo regional para algunos sitios, no podemos soslayar los impactos desfavorables que éste ha generado y la exclusión que se ha hecho de la población local, en tanto destinatarios de ese desarrollo.

En la actividad turística, como en muchas otras, por lo general se resaltan como atributos principales los beneficios económicos que el turismo propicia, olvidándose con frecuencia que muchas veces los costos sociales y ecológicos que la práctica de la actividad trae consigo resultan más elevados e irreversibles que los beneficios económicos que se puedan generar (Bringas, 1997). A pesar de ello, en el caso particular del ecoturismo, no se puede soslayar el hecho de que éste, mal manejado, también puede ocasionar los mismos efectos indeseables que el turismo de masas provoca. Lamentablemente, en países en desarrollo como México, todavía el prefijo "eco" del turismo no es garantía de sustentabilidad ni de respeto a la naturaleza, y sí puede ser un anzuelo eficaz para atraer financiamiento externo.

Las perspectivas del turismo mundial señalan una marcada expansión por los viajes a la naturaleza, sobre todo de los países industrializados hacia los que se encuentran en vías de desarrollo. En este contexto, el ecoturismo puede ser una oportunidad para reorientar al turismo hacia formas novedosas de ensayar el tiempo libre en actividades que redunden en beneficios personales, al mismo tiempo que se obtienen ingresos y se conservan los recursos naturales y culturales. Con todo, puesto que existen algunos problemas conceptuales para delimitar con claridad las fronteras entre los distintos tipos de turismo basados en la naturaleza, algunos de los tour operadores internacionales han aprovechado esta confusión para promover estos productos de modo masivo, encubriéndolos bajo el manto del turismo verde.

Lo anterior nos ha llevado a considerar que no todas las variedades de turismo alternativo basado en la naturaleza son sustentables en sentido ecológico, como se vio en el ejemplo de las carreras fuera de carretera, ni que los recursos económicos permanezcan en las comunidades receptoras, como lo muestra el caso de la observación de ballenas. En ambos casos se ha comprobado que existe un vasto interés por masificar estos destinos. Así mismo, resulta contradictorio que a pesar de que se conocen los riesgos que conlleva este tipo de turismo, se quiera promover en áreas tan frágiles como lo son las ANP, sin garantizar un control en la afluencia de visitantes y sin asegurar que los ingresos gene- 
rados se queden en la localidad. Lo ideal sería que la distribución de ingresos resultase a la inversa de como ha ocurrido hasta hoy, es decir que la mayor parte de éstos beneficie a las comunidades receptoras.

El ecoturismo tiene un enorme potencial para el país y puede ser una opción viable para diversificar la oferta de actividades, al mismo tiempo que se obtienen ventajas económicas. Sin embargo, para que esta actividad obedezca de verdad a factores de índole ecológica, social y cultural, y no sólo económica, se debe tratar de involucrar a las comunidades locales para la conservación y preservación de estos sitios. 


\section{Cuadro 1}

Diferencias entre el modelo turístico tradicional y el alternativo

\begin{tabular}{|l|l|}
\hline \multicolumn{1}{|c|}{ Turismo convencional } & \multicolumn{1}{c|}{ Turismo especializado } \\
\hline Producto tipificado & Producto único \\
\hline $\begin{array}{l}\text { Fuerte inversión inicial en } \\
\text { infraestructura turística }\end{array}$ & $\begin{array}{l}\text { Fuerte inversión inicial en } \\
\text { conocimiento, organización e } \\
\text { información }\end{array}$ \\
\hline $\begin{array}{l}\text { Altos costos iniciales para } \\
\text { creación de infraestructuras y } \\
\text { equipamientos }\end{array}$ & $\begin{array}{l}\text { Costos necesarios para crear } \\
\text { infividades y facilitar experiencias, } \\
\text { adecuados }\end{array}$ \\
\hline Alto impacto inicial & Crecimiento gradual \\
\hline Promoción en medios masivos & Promoción especializada \\
\hline $\begin{array}{l}\text { Criterio de selección de } \\
\text { mercados: Niveles de ingreso }\end{array}$ & $\begin{array}{l}\text { Criterio de selección de mercados: } \\
\text { Grupo de interés }\end{array}$ \\
\hline $\begin{array}{l}\text { Objeto de la promoción: } \\
\text { Instalación turística }\end{array}$ & $\begin{array}{l}\text { Objeto de la promoción: } \\
\text { Actividades y experiencias }\end{array}$ \\
\hline Estilo de vida estándar & Estilo de vida personal \\
\hline $\begin{array}{l}\text { Comportamiento del turista: } \\
\text { Observar sin interactuar }\end{array}$ & $\begin{array}{l}\text { Comportamiento del turista: } \\
\text { Experimentar en la región }\end{array}$ \\
\hline $\begin{array}{l}\text { Programa de viaje: } \\
\text { Preestablecido }\end{array}$ & Programa de viaje: Abierto \\
\hline Riesgo: Pérdida de control & $\begin{array}{l}\text { Riesgo: Complejidad de la } \\
\text { organización }\end{array}$ \\
\hline
\end{tabular}

Fuente: SECTUR, 1993. 


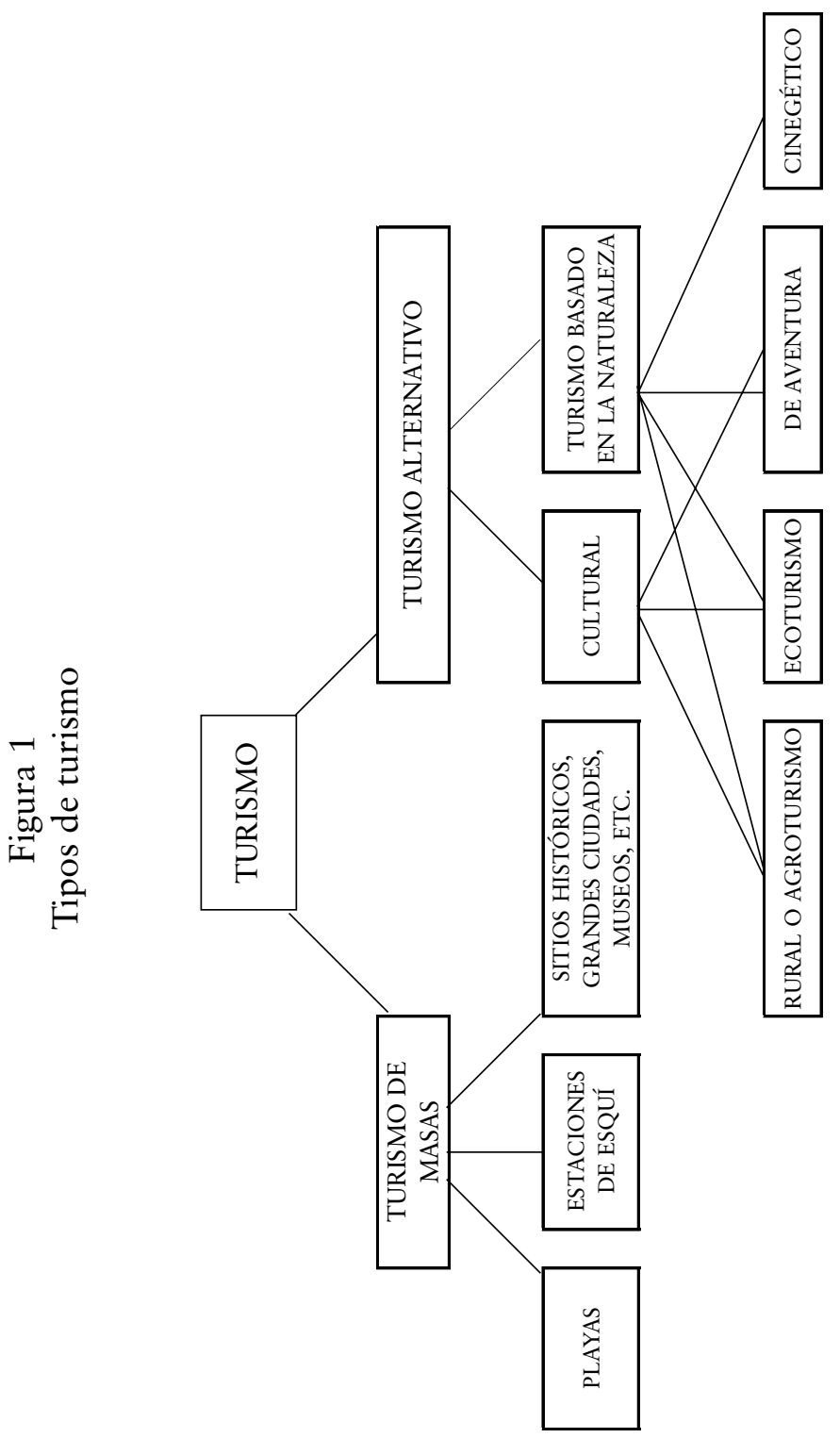




\section{Mapa 1}

Áreas naturales protegidas y carreras fuera de carretera Baja California, México

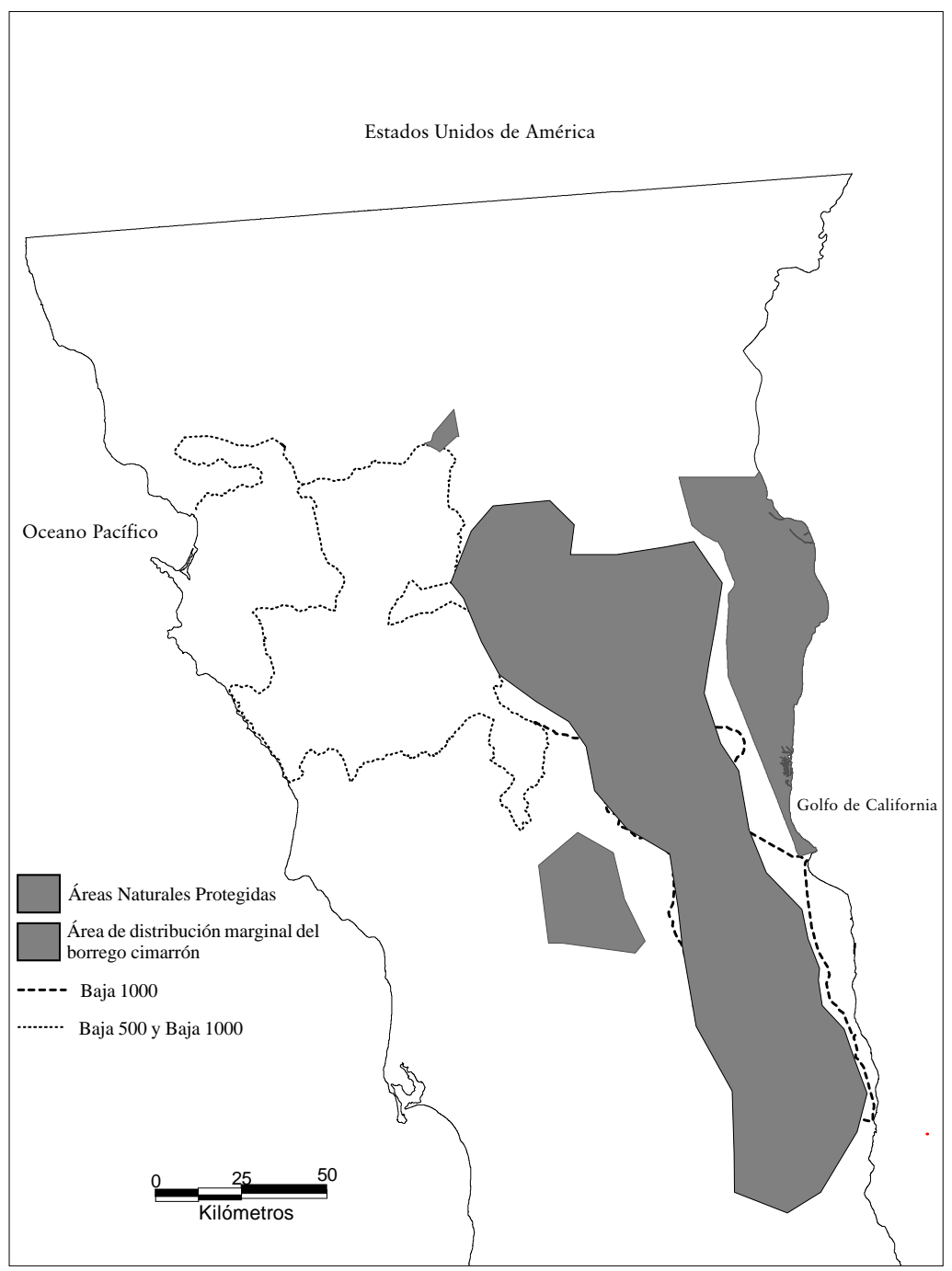




\section{Bibliografía}

Andren, Henrik (1994), "Effect of habitat fragmentation on birds and mammals in landscape with different proportions of suitable habitat: A review", Oikos, núm. 71, pp. 355-366.

Baker (1990) y Prescott-Allen (1986), cit. en OMT y PNUMA (1992), Directrices: Ordenación de los parques nacionales y de otras zonas protegidas para el turismo, Madrid, 1992, p. 7.

Boo, Elizabeth (1990), Ecotourism. The Potentials and pitfalls, Washington, D. C., World Wild Fund.

- (1992), The ecotourism. Planning for development and management, Wildlands and Humans Needs. A program of World Wildlife Fund, whN Technical Paper Series, núm. 2, julio.

Brattstrom, Bayard H. y Michael C. Bondello (1983), "Effects of off-road vehicle noise on desert vertebrates", en H. R. Webb y H. G. Vilshire (eds.), Environmental effects of offroad vehicles, Nueva York, Springer Verlag, pp. 167-206.

Bringas Rábago, Nora L. (1997), "Las dos caras del turismo: beneficios económicos contra costos sociales, culturales y ecológicos: el caso de México", Fermentum, Miradas sobre América Latina, año 7, núm. 18, enero-abril, pp. 89116, Mérida, Venezuela.

Budowski, Támara (1989), "Ecoturismo a la Tica”, Tecnitur International Magazine, Costa Rica, p. 75.

Burton, Fiona (1998), "Can ecotourism objetives be achieved?", Annals of Tourism Research, vol. 25, núm. 3, p. 756.

Butler, Judith (1993), cit. en Geoffrey Wall (1997), “Is ecotourism sustainable?", Environmental Management, vol. 21, núm. 4, p. 29.

Callicot, J. Baird y Karen Munford (1997), "Ecological sustainability as a conservation concept", Conservation Biology, vol. 11, núm. 1, pp. 32-40. 
Cazes, Georges (1992), Tourisme et tiers monde. Un bilan controversé. Les nouvelles colonies de vacances?, Tomo 2, París, L'Harmattan, col. Tourismes et Societés.

Ceballos Lascurain, Héctor (1988), “The Future of Ecotourism”, Mexico Journal, núm. 17, pp. 13-14.

Dedina, Serge y Emily Young (1995), Conservation and development in the gray whale lagoons of Baja California Sur, Mexico. Final Report to the U. S. Marine Mammal Commission. Contract T1015592. http://scilib.ucsd.edu/sio/ guide/z-serge.html

Delgadillo, José (1988), "Los recursos vegetales de Baja California, su conservación y protección”, Travesía, núm. 12, pp. 25-31, UABC.

Dregne, Harold E. (1983), "Soil and soil formation in arid regions”, en H. R. Webb y H. G. Vilshire (eds.), Environmental effects of off-road vehicles, Nueva York, Springer Verlag, pp. 15-30.

Escofet, Anamaría y Alberto Carvacho (1988), "The effect of tourist activity on coastal ecosystems of Baja California", en S. F. Ferraras y G. Pararas-Carayannis (eds.), Proceedings of the International Conference on Natural and ManMade Coastal Hazards, Ensenada, Baja California, pp. 194198.

Flores Villela, Óscar y Patricia Gerez (1988), Conservación en México: Sintesis sobre vertebrados terrestres, vegetación y uso del suelo, INIREB-Conservación Internacional.

Goodwin (1996), cit. en Fiona Burton (1998), "Can ecotourism objectives be achieved?", Annals of Tourism Research, vol. 25, núm. 3, p. 756.

Kockelman, William J. (1983a), “Management practices”, en H. R. Webb y H. G. Vilshire (eds.), Environmental effects of off-road vehicles, Nueva York, Springer Verlag, pp. 447493. 
_ (1983b), "Introduction”, en H. R. Webb y H. G. Vilshire (eds.), Environmental effects of off-road vehicles, Nueva York, Springer Verlag, pp. 1-14.

Lathrop, Earl W. y Peter G. Rowlands (1983), "Plant ecology in deserts: an overview", en H. R. Webb y H. G. Vilshire (eds.), Environmental effects of off-road vehicles, Nueva York, Springer Verlag, pp. 113-152.

Lineham, John R. y Mier Gross (1998), "Back to the future, back to basics: the social ecology of landscapes and the future of landscape planning", Landscape and Urban Planning, núm. 42, pp. 207-223.

Mann, W. Guillermo (s/f), Conservación y desarrollo: marco conceptual, p. 27, mimeo.

Marajh, Oumatie y Deborah R. Meadows (1992), "Ecotourism in Latin America and the Caribbean: Strategies and implications for development", ponencia presentada en Envitour-Vienna'92, 10 a 12 de noviembre, Viena.

Martínez Gallardo, Roberto y B. Ricardo Eaton González (s/f), "Mamíferos terrestres de la Cuenca del Río Tijuana", Ensenada UABC (mimeo.).

Mendelsohn, Robert (1994), "The role of ecotourism in sustainable development", en Gary K. Meffe y C. Ronald Carroll, Principles of conservation biology, Sunderland, Mass., Sinauer Associates, pp. 511-515.

Noss, Reed F. (1996), "Conservation of biodiversity at the landscape level”, en R. C. Szaro y D. W. Johnston, Biodiversity and managed landscape. Theory and practice, Nueva York, Oxford University Press, pp. 574-589.

OMT (1998), Turismo Panorama 2020. Nuevas previsiones de la Organización Mundial del Turismo. Avance actualizado, junio, Madrid, omT. 
(1992), "Aliar el medio ambiente, la economía y el turismo", Informe de la XXIV Reunión de la Comisión de la OMT para África, septiembre, Madrid, OMT.

— y PNUMA (1992), Directrices: ordenación de los parques nacionales y de otras zonas protegidas para el turismo, Madrid, p. 7.

Padget, Tim y Sharon Begley (1996), "Les baleines victimes de la vague verte", Courrier International, núm. 283, 4 a 10 de abril, París.

Parkhurst, J. (1988), “Baja and motorcycles. The world's most exciting dirt biking”, Baja Traveler, vol. 1, núm. 1, pp. 5053.

Pearce, Douglas (1988), Desarrollo turístico, su planificación y ubicación, México, Trillas.

Peck, S. (1998), Planning for biodiversity. Issues and examples, Island Press, Washington, D.C.

Pickett, S. T. A. y P. S. White (1981), The ecology of natural disturbance and patch dynamics, Orlando, Academic Press.

Secretaría de Turismo (SECTUR) (1998a), Estadísticas básicas de la actividad turística 1997, México, SECTUR.

- (1998b), Movimiento y gasto de turistas internacionales en el primer semestre de 1998 y pronóstico de cierre del mismo año, México, Subsecretaría de Desarrollo Turístico.

_ (1993), “El Turismo en México, 1993”, Folleto de Información estadística, México, SECTUR, 112 p.

Secretaría de Turismo del Estado de Baja California (1997), Estudio de impacto Ambiental Carreras Fuera de la Carretera, Tijuana, B. C., SECTURE.

Thibal, Suzanne (1996), "Le tourisme rural: les produits, le marché, les méthodes de commercialisation", en oMT, Une 
solution pour l'emploi, le développement local et l'environnement, Israel, seminario conjunto CEU-ETC.

Ungefug, Hans-Georg (1992), “Tour operators and suppliers see tourism to mediterranean as being in grip of transition. More round trips and quality gaining ground", FVW 27/ 92.

Wall, Geoffrey (1997), "Is ecotourism sustainable?”, Environmental Management, vol. 21, núm. 4, p. 29.

Wilshire, Howard G. (1983), "The impact of vehicles on desert soil stabilizaers”, en H. R. Webb y H. G. Wilshire (eds.), Environmental effects of off-road vehicles, Nueva York, Springer Verlag, pp. 31-50.

Ziffer, Karen A. (1989), Ecotourism: the uneasy alliance, Washington, D. C., Conservation International, Ernst \& Young, Fall, 36 p. 
